\title{
Aplasia and Agenesis of the Frontal Sinus in Turkish Individuals: A Retro- spective Study Ising Dental Volumetric Tomography
}

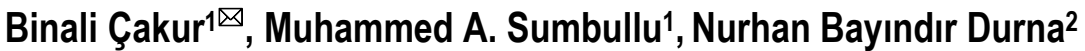 \\ 1. Department of Oral Diagnosis and Oral Radiology, Faculty of Dentistry, Ataturk University, Erzurum, Turkey \\ 2. Numune Hospital, Erzurum, Turkey
}

$\triangle$ Corresponding author: Dr. Binali ÇAKUR, Department of Oral Diagnosis and Radiology, Faculty of Dentistry, Ataturk University, 25240 Erzurum, TURKEY. Business phone: +904422311765; Fax: +904422360945; E-mail: bcakur@atauni.edu.tr

(C) Ivyspring International Publisher. This is an open-access article distributed under the terms of the Creative Commons License (http://creativecommons.org/ licenses/by-nc-nd/3.0/). Reproduction is permitted for personal, noncommercial use, provided that the article is in whole, unmodified, and properly cited.

Received: 2011.01.25; Accepted: 2011.03.30; Published: 2011.04.08

\begin{abstract}
Agenesis of the paranasal sinuses is an uncommon clinical condition that appears mainly in the frontal (I2\%) and maxillary (5-6\%) sinuses; in some populations, it appears at a higher proportion. This study investigated the prevalence of agenesis of the frontal sinuses using dental volumetric tomography (DVT) in Turkish individuals. The frontal sinuses of 410 patients were examined by DVT scans in the coronal planes for evidence of the absence of the frontal sinuses. A bilateral and unilateral absence of the frontal sinuses was seen in $0.73 \%$ and $1.22 \%$ of cases, respectively. In one case, both agenesis and aplasia of the frontal sinus was seen $(0.24 \%)$. The low percentage of frontal sinus agenesis must be considered during pre-surgical planning related to the sinuses. DVT may be used as a diagnostic tool for the examination of frontal sinus aplasia.
\end{abstract}

Key words: Frontal sinus agenesis, Dental volumetric computed tomography, Paranasal Sinuses

\section{Introduction}

The frontal sinus is contained within the frontal bone and is situated behind the supercilliary arch $[1,2]$. The two irregularly shaped frontal sinuses are separated completely by a bone septum, which is approximately located in the midline [2-4]. The frontal sinus is vulnerable because of its close relationship to other anatomical structures, such as the anterior skull base or the orbit [5]. The frontal sinuses arise from one of several outgrowths that originate in the region of the frontal recess of the nose, and their site of origin can be identified on the mucosa as early as 3 to 4 months in utero. Less commonly, the frontal sinus develops from anterior ethmoid cells of the infundibulum [6-8]. The frontal sinuses are essentially the only paranasal sinuses that are absent at birth, because, on average, these sinuses do not reach up into the frontal bone until about the age of 6 years. Their develop- ment is quite variable but effectively appears to start only after the second year of life $[4,8,9]$. By the age of 4 years, the average cranial extent of the frontal sinus reaches half the height of the orbit and extends just above the top of the most-anterior ethmoid cells. By the age of 8 years, the top of the frontal sinuses is at the level of the orbital roof, and by the age of 10 years, the sinuses extend into the vertical portion of the frontal bone. The final adult proportions are reached only after puberty $[4,8-10]$. The volume of the frontal sinus is highly variable, ranging from 0 to $37 \mathrm{cc}$ with a mean of $10 \mathrm{cc}$ [2]. Variability in the size and aspect of the frontal sinus is usually found in individuals of the same age [11,12]. Because the left and right frontal sinuses develop independently, a significant asymmetry between these sinuses can arise in the same individual [2]. 
The paranasal sinuses have been thought to contribute to voice resonance, to humidify and warm the inspired air, to increase the olfactory membrane area, to absorb shock to the face and head, to provide thermal insulation for the brain, to contribute to facial growth, to represent vestigial structures, and to lighten the skull and facial bones [8].

The exact drainage system of the frontal sinus depends on its embryologic development $[2,13]$. The drainage usually occurs directly into the frontal recess [14] or into the frontal recess by way of rudimentary anterior ethmoidal cells [2,13-15]. The frontal recess is a deep anterosuperior depression in the middle meatus, which forms a closed channel in its upper surface called the frontonasal duct [13-16]. The shape, dimensions, and limits of the frontal recess are determined by its surrounding structures [2], and a frontal sinus cannot exist without a recess [5]. However, anatomical variants may alter the configuration of the frontal recess $[4,8]$. When a frontal sinus is agenetic, the contralateral sinus may expand and cross the midline toward the agenetic side, which mimics the presence of bilateral frontal sinuses [1]. CT scans of agenetic patients show almost normal frontal recesses and sinuses, although there is only one frontal sinus ostium. The size of the sinus and, therefore, its anatomic relationships also depend upon the extent of pneumatization [11]. The extent of pneumatization results in the individual size and shape of the frontal sinus. An absence of pneumatization in the frontal bone results in frontal sinus aplasia [1]. This kind of variation should make sense for otolaryngologists because complications may develop during endoscopic surgery for such an agenetic frontal sinus if it is not detected in advance [5]. Although frontal sinus aplasia is not rare in the literature, the frequency of frontal sinus agenesis is variable between different populations [1,3,5, 17-19]. Occasionally, one or both sinuses may be absent. The prominence of supercilliary arcs does not indicate the absence, presence or size of the frontal sinus [3].

The objective of this study was to investigate the prevalence of frontal sinus aplasia and agenesis using dental volumetric tomography in a population of Turkish individuals.

\section{Materials and methods}

We designed a retrospective study consisting of images of 410 patients (190 male, 220 female; aged 15 to 69 years; mean age, 33 years 7 month \pm 13 years 9 month) who presented at our clinic between June 2008 and September 2010. Dental volumetric tomography (NewTom-FP; Quantitative Radiology, Verona, Italy) scanning was performed on patients who were resting in supine positions. Positioning of the patients' heads was performed using two light-beam markers. The vertical positioning light was aligned with the patients' mid-sagittal lines, which helped to keep the head centered with respect to the rotational axis. The lateral positioning light was centered at the level of the sinus, indicating the optimized center of the reconstruction area. In addition, the head position was adjusted in such a way that the hard palate was parallel to the floor, while the sagittal plane was perpendicular to the floor. Dental volumetric tomography DVT scans with $0.5-\mathrm{mm}$ slices in the coronal plane were obtained. Imaging parameters were $k V=110$, $\mathrm{mA}=10$, and $\mathrm{FOV}=140 \mathrm{~mm}$. The output was automatically adjusted during a $360^{\circ}$ rotation according to tissue density (automatic exposure control system). Two dental radiologists in this study evaluated the DVT images using DVT software (Quantitative Radiology, NNT Software version 2.21, Verona, Italy) with respect to aplasia and agenesis of the frontal sinus on coronal images based on a method proposed by Eggesbø et al. [20]. In this method, frontal sinus aplasia was defined as the absence of frontal bone pneumatization with no ethmoid cells extending above a line tangential to the supraorbital margin. Frontal sinus aplasia was also defined by an oval-shaped sinus with the lateral margin medial to a vertical line drawn through the middle of the orbit (vertical line) with a smooth superior margin and with an absence of the sinus septa (Fig. 1).

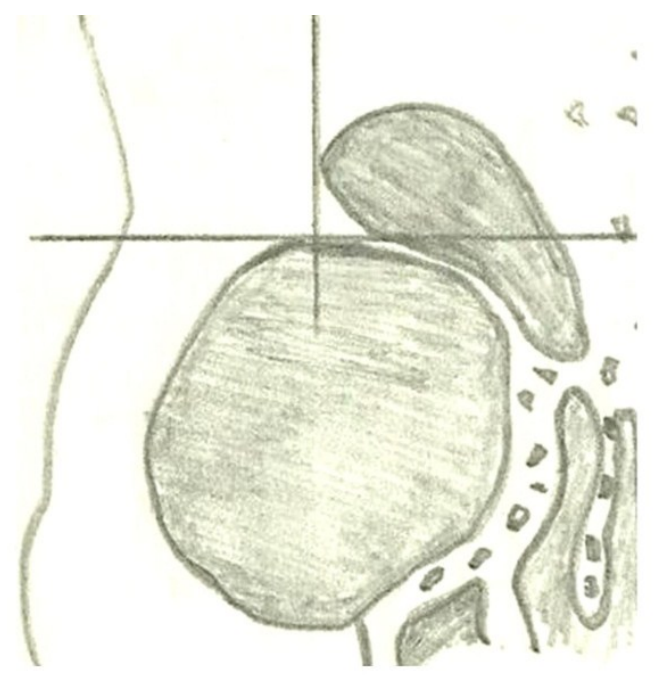

Fig. I. Frontal sinus aplasia is defined as the absence of frontal bone pneumatization with no ethmoid cells extending above a line tangential to the supraorbital margin (horizontal line). Frontal sinus aplasia is also defined by an oval-shaped sinus with the lateral margin medial to a vertical line drawn through the middle of the orbit (vertical line) with a smooth superior margin and an absence of the sinus septa [20]. 
Table I. Frequency of frontal sinus agenesis

\begin{tabular}{lcccc}
\hline Sex & $\mathbf{n}$ & \multicolumn{2}{c}{ Frontal Sinus Agenesis } \\
\cline { 3 - 5 } & & Bilateral & \multicolumn{2}{c}{ Unilateral } \\
\cline { 3 - 5 } & & $1(0.24 \%)$ & $2(0.49 \%)$ & $0(0.0 \%)$ \\
\hline Male & 190 & $2(0.49 \%)$ & $1(0.24 \%)$ & $2(0.49 \%)$ \\
Female & 220 & & $3(0.73 \%)$ & $2(0.49 \%)$ \\
Total & 410 & $3(0.73 \%)$ & \multicolumn{2}{c}{$5(1.22 \%)$} \\
\hline
\end{tabular}

Images were viewed in a darkened room on 2 computers with 17-inch LCD monitors with the same screen resolution. Because the frontal sinuses do not attain adult size until puberty, the minimum age of these cases was 15 years. A weighted kappa test was performed to determine the reliability of this method. Intra- and inter-observer agreement was analyzed using the weighted kappa test.

\section{Results}

In the DVT scans, both agenesis (on the right) and aplasia (on the left) were seen in one case $(0.24 \%$; Fig. 2). The results from the present study are summarized in Table 1. The weighted kappa values for intra-observer reliability were 0.89 and 0.93 for the first and second observer, respectively. The weighted kappa value for inter-observer reliability between observers 1 and 2 was 0.86 .

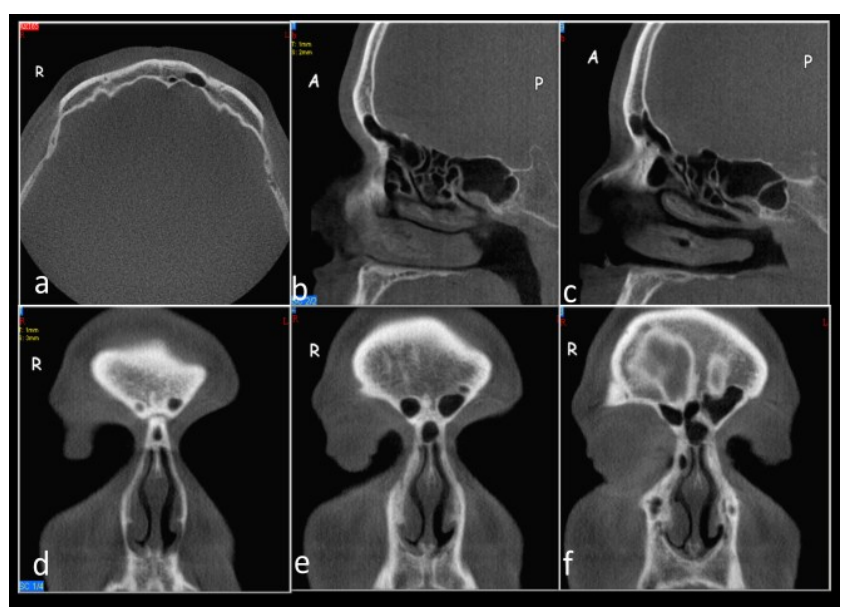

Fig. 2. Unilateral absence of the frontal sinus; on the right, the absence of the frontal sinus, and on the left, the limited aeration of the frontal sinus; axial view (A), right sagittal view (B), and left sagittal view (C); sequential coronal slices of frontal sinuses (D, E, F).

\section{Discussion}

The variations in the anatomy of the frontal sinus may be critical for morphological or forensic investigations and for neurosurgeons performing pterional or supraorbital craniotomy because of the proximity of the sinus to the orbit and the anterior skull base [5]. The frequency of bilateral absence of the frontal sinus has been reported in $3-4 \%$ to $10 \%$ of several populations [1]. However, this frequency was significantly higher in some populations, including Alaskan Eskimos (25\% in males and $36 \%$ in female) and Canadian Eskimos ( $43 \%$ in males and $40 \%$ in female) $[21,22]$. According to the literature, the frequency of a bilateral absence of the frontal sinuses (Fig. 3) in this study was lower than that reported for most ethnic populations. In addition, previous researchers have reported that a greater frequency of bilateral frontal sinus agenesis occurs among females than among males, which is similar to the findings in our study (Table 1) [1,5, 21].

The incidence of a unilateral absence of the frontal sinus has been reported to be between $0.8 \%$ and $7.4 \%[1,18,23]$. In this study, the incidence of a right unilateral frontal sinus agenesis was $0.49 \%$ in males and $0.24 \%$ in females (Fig. 4), whereas the incidence of a left unilateral sinus absence was $0.49 \%$ in females and was not observed in males (Table 1). Yoshino et al. [24] reported that the frequency of a unilateral sinus absence was $14.3 \%$ for males $(9.5 \%$ right, $4.8 \%$ left) and $7.1 \%$ for females (7.1 right, $0.0 \%$ left). Nowak and Mehls [25] reported that the frequency of a unilateral absence of the frontal sinus was $7.4 \%$ for adults $(4.2 \%$ right, $3.2 \%$ left). The frequency of a unilateral sinus absence was reported to be $1 \%$ by Schuller [26], which is similar to the frequency in our study $(1.22 \%)$. Spaeth et al. [27] noticed that agenesis of the frontal sinus was more frequent in women. Aydinlioğlu et al. [1] reported that the incidence of a left unilateral agenesis of the frontal sinus was higher than that of a right unilateral agenesis in men, which was the opposite of the case in women. In addition, the authors also reported that a greater frequency of unilateral agenesis of the sinus occurs among females. In contrast with the study performed by Aydinlioğlu et al. [1], however, we found a higher frequency of a right unilateral absence of the frontal sinus than a left unilateral absence in men, but our results in women were similar to those of Aydinlioğlu et al. [1]. Additionally, we found a higher frequency of left unilateral absence in females than in the males, in agreement with other studies $[1,5,21]$. 


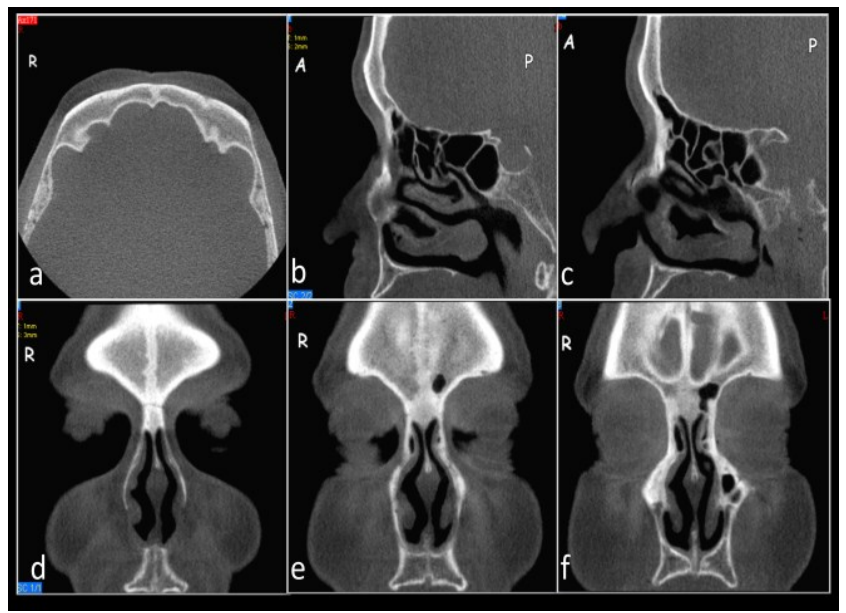

Fig. 3. Bilateral absence of the frontal sinuses; axial view $(A)$, right sagittal view (B), left sagittal view (C); sequential coronal slices of frontal sinuses (D, E, F).

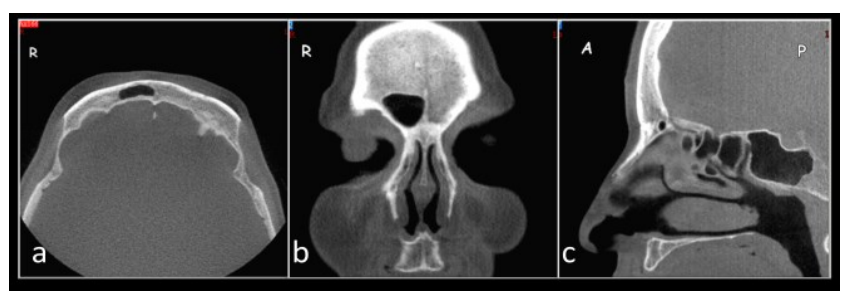

Fig. 4. Unilateral absence of the frontal sinus; on the left, the absence of frontal sinus; axial view $(A)$, coronal view $(B)$, and sagittal view (C).

The frequency of bilateral and unilateral agenesis of the sinuses in this study differed from frequencies reported for most ethnic populations. The discrepancy between the frequency in our population and that in other populations may be due to the number of patients examined, the patient sample, and the difference in the examining techniques and equipment. In addition, constitutional (age, gender, hormones, and craniofacial configuration) and environmental (climatic conditions and local inflammations) factors control the frontal sinus configuration within each population and contribute to the abnormal development of the frontal sinus $[1,5,18,27]$. There is a direct relationship between the mechanical stresses of mastication and frontal sinus enlargement $[8,28,29]$ and if there is persistence of a metopic suture, the frontal sinuses are small or absent [8-10]. The form of the face and forehead in the presence of a metopic suture conforms to the evolutionary trend of the skull [30]. In addition, Eggesbø et al. [20] suggested that anatomic paranasal sinus variations might be more common in genetically verified cystic fibrosis patients due to less well-developed paranasal sinuses.

In conclusion, the low percentage of the frontal sinus agenesis must be taken into consideration during the pre-surgical planning related to the sinus. In addition, a greater frequency of bilateral frontal sinus agenesis occurs among females than among males. In males, unilateral frontal sinus agenesis might be more common on the right side, but in females, the opposite is the case. The preoperative recognition of the frontal sinuses is a prerequisite for any successful surgical procedure because of individual anatomic variations. Therefore, the analysis of DVT images of the frontal sinus is a useful tool to identify its size and configuration and to minimize the risk factors associated with surgical procedures.

\section{Conflict of Interest}

The authors have declared that no conflict of interest exists.

\section{References}

1. Aydinlioğlu A, Kavakli A, Erdem S. Absence of Frontal Sinus in Turkish Indivudials. Yonsei Med J. 2003;44(2):215-8.

2. Levine HL, Clemente MP. Sinus surgery: endoscopic and microscopic approaches. In: Clemente MP, ed. Surgical Anatomy of the Paranasal Sinus. Stuttgart: Thieme; 2003: 1-55.

3. Pondé JM, Metzger P, Amaral G, Machado M, Prandini M. Anatomic variations of the frontal sinus. Minim Invasive Neurosurg. 2003;46(1):29-32.

4. Manolidis S, Hollier LH. Management of Frontal Sinus Fractures. Plast Reconstr Surg. 2007;120: 32-48.

5. Ozgursoy OB, Comert A, Yorulmaz I, Tekdemir I, Elhan A, Kucuk B. Hidden unilateral agenesis of the frontal sinus: human cadaver study of a potential surgical pitfall. Am J Otolaryngol. 2010;31(4):231-4.

6. Tezer MS, Tahamiler R, Çanakçığlu S. Computed Tomography Findings in Chronic Rhinosinusitis Patients with and without Allergy. Asian Pac J Allergy Immunol. 2006;24:123-7.

7. Schaeffer J. The Embryology, Development and Anatomy of the Nose, Paranasal Sinuses, Nasolacrimal Passageways and Olfactory Organs in Man. Philadelphia: P Blakiston's Son; 1920.

8. Som PM, cCurtin HD. Head and neck imaging. In: Som PM, Shugar JMA, Brandwein MS, eds. Anatomy and Physiology, 4th ed. St. Louis: Mosby; 2003:98-100.

9. Dodd G, Jing B. Radiology of the Nose, Paranasal Sinuses and Nasopharynx. Baltimore: Williams \& Wilkins. 1977:59-65.

10. Hollinshead W. The nose and paranasal sinuses. In: Hollinshead W, ed. Anatomy for Surgeons. New York: Hoeber-Harper. 1954:229-281.

11. Fatua C, Puisorub M, Rotaruc M, Truta AM. Morphometric evaluation of the frontal sinus in relation to age. Trutad Ann Anat. 2006;188:275-80.

12. Williams PL, Bannister LH, et al. Gray's Anatomy, 38th ed. London: Churchill Livingstone; 1995: 1635.

13. Duvoisin B, Schnyder P. Do abnormalities of the frontonasal duct cause frontal sinusitis? A ct study in 198 patients. AJA. 1992;159:1295-8.

14. Kaspar KA. Nasofrontal connections: a study based on one hundred consecutive dissections. Arch Otolaryngol. 1936;23:322-43. 
15. Agrifoglio A, Terrier G, Duvoisin B. Etude anatomique et endoscopique de I'ethmoide antérieur. Ann Otolaryngol Chir Cervicofac. 1990;107:249-58.

16. Heller EM, Jacobs JB, Holliday RA. Evaluation of the frontonasal duct in frontal sinus fractures. Head Neck. 1989;11:46-50.

17. Harris AM, Wood RE, Nortjé CJ, Thomas CJ. The frontal sinus: forensic fingerprint? A pilot study. J Forensic Odontostomatol. 1987;5:9-15.

18. Kountakis S, Senior B, Draf W. The frontal sinus. Heidelberg:Springer-Verlag; 2005.

19. Shah RK, Dhingra JK, Carter BL, et al. Paranasal sinus development: a radiographic study. Laryngoscope. 2003;113:205-9.

20. Eggesbø HB, Søvik S, Dølvik S, Eiklid K, Kolmannskog F. CT characterization of developmental variations of the paranasal sinuses in cystic fibrosis. Acta Radiol. 2001;42(5):482-93.

21. Koertvelyessy T. Relationship between the frontal sinus and climatic conditions: a skeletal approach to cold adaptation. Am J Phys Anthropol. 1972;34:161-72.

22. Hanson CL, Owsley DW. Frontal sinus size in Eskimo population. Am J Phys Anthropol. 1980;53:251-5.

23. Harris AMP, Wood RE, Nortje CJ, Thomas CJ. Gender and ethnic differences of the radiographic image of the frontal region. J Forensic Odontostomatol. 1987;5:51-7.

24. Yoshino M, Miyasaka S, Sato H, Seta S. Classification system of frontal sinus patterns by radiography. Its application to identification of unknown skeletal remains. Forensic Sci Int. 1987;34:289-99.

25. Nowak R, Mehls G. Die apllasien der sinus maxillaries und frontales unter besenderer Berucksichtigung der pneumatization bei spalttragern. Anat Anz. 1977;142:441-450.

26. Schuller A. Note on the identification of skulls by X-ray pictures of the frontal sinuses. Med J Aust. 1943;1:554-556.

27. Spaeth J, Krugelstein U, Schlondorf G. The paranasal sinuses in CT-imaging: development from birth to age 25. Int J Pediatr Otorhinolaryngol. 1997;39:25-40.

28. Goss C. Gray's Anatomy of the Human Body, 27th ed. Philadelphia: Lea \& Febiger; 1963.

29. Shapiro R, Schorr S. A consideration of the systemic factors that influence frontal sinus pneumatization. Invest Radiol. 1980;15:191-202.

30. Torgersen J. The developmental genetics and evolutionary meaning of the metopic suture. Am J Phys Anthropol. 1951;9(2):193-210. 